\title{
Factors Associated with Length of Intensive Care Unit Stay Following Cardiac Surgery in Cardiac Center Ethiopia, Addis Ababa, Ethiopia: Institution Based Cross Sectional Study.
}

\author{
Tesfaye Techane $\mathbb{D}^{\prime}$, Eriste Nigussa', Feyissa Lemessa', Tigist Fekadu² \\ 'Saint Paul's Hospital Millennium Medical College, School of Nursing and Midwifery, Addis Ababa, Ethiopia; ${ }^{2}$ Saint Paul's Hospital Millennium Medical \\ College, Cardiothoracic Nursing, Addis Ababa, Ethiopia \\ Correspondence: Tesfaye Techane, Email Tesfaye.techane@sphmmc.edu.et
}

\begin{abstract}
Background: Following cardiac surgery intensive care unit (ICU) is the immediate place to stay. The length of stay (LOS) in the ICU is the average duration patients stay in ICU following cardiac surgery. Length of stay is one of the most significant factors that face hospitals today. Prolonged ICU stay is an important determinant of increased suffering and death after cardiac procedures because there are too many identified and unidentified factors that determine ICU stay. The aim of this study is therefore to assess factors associated with length of ICU stay following cardiac surgery in Cardiac Center Ethiopia.

Methods: Institution-based descriptive cross-sectional study was conducted on patients with cardiac surgery at Cardiac Centre Ethiopia, from November to March 2021. Two hundred forty-eight (248) charts were selected by lottery method. Data were entered into Epi-info 7.2 and export to SPSS version 25.0 for analysis. Descriptive statistics such as mean, frequency and percentages were calculated to describe and displayed in tables, graphs and charts. Binary logistic regression employed to see basic association of each independent variable with dependent variables. Multivariate logistics regression was employed to control the effect of confounding in 95\% confidence level at P-value less than 0.05 .

Results: In this study the length of Intensive Care Unit stay following cardiac surgery was $3.79 \pm 1.7$ days ranging from 1 to 9 days, $126(50.8 \%)$ had longer ICU stay after cardiac surgery in Cardiac Centre Ethiopia. Smoking history, having more than one surgery procedure and post cardiac surgery have been found significantly related with prolonged ICU stay following cardiac surgery in the current study area at $\mathrm{p}$ value $\leq 0.05$.

Recommendation: We recommend hospital managers and cardiac hospitals to prevent post cardiac surgery complications as these were found the main determinants of prolonged ICU stay in this study. We Further recommend for prospective follow-up study to examine whether these findings represent the true figure in this study.
\end{abstract}

Keywords: length, intensive care unit, stay, factors, cardiac surgery

\section{Background}

Cardiovascular diseases and Rheumatoid heart disease are "disorders that affect the structure and function of the heart and blood vessels". ${ }^{1}$ Globally cardiovascular disease (CVD) and Rheumatoid Heart Disease (RHD) are the leading cause of death. ${ }^{2}$ Cardiovascular diseases (CVDs) and CVD-related conditions remained the leading cause of morbidity and mortality in the developed countries like the USA. ${ }^{3}$ Too many lost their lives each year from cardio vascular disease compared to other causes of death and illness.

Nearly 18 million deaths were recorded and related disorders from cardiovascular and related disorders in 2016, which accounts around $31 \%$ of total deaths. Heart attack and stroke holds the major proportion $(85 \%)$ of the disease. ${ }^{4-6}$ More than $75 \%$ of cardiovascular diseases deaths happened in low- and middle-income countries. ${ }^{2,7,8}$ 
Most cardiovascular diseases can be prevented by addressing behavioural risk factors such as tobacco use, unhealthy diet and obesity, physical inactivity and harmful use of alcohol using population-wide strategies. ${ }^{9-11}$

According to the World Health Organization (WHO) report in 2011 " $34 \%$ of the Ethiopian population was dying from non-communicable diseases, accounting 15\% national cardiovascular disease prevalence in the country." Besides Global Burden of Disease (GBD) estimated that in "Ethiopia 800 of 100,000 people are dying because of non-communicable diseases", and more significantly 450 per 100,000 deaths were recorded because of cardiovascular disease. ${ }^{12,13}$

There are a lot of reasons that contribute to the higher prevalence of the cardiovascular disease. Particularly due to dominance of urbanization and incidence of morbidities affecting the cardiovascular system in developing countries, as well as rheumatic heart disease and malaria cardiac and vascular effects. ${ }^{14,15}$

Surgical procedures are most likely inevitable for patients with cardiovascular diseases both for diagnostic like; Cardiac Catheterization $(\mathrm{CC})^{16-18}$ and treatment purposes like Coronary Artery Bypass Grafting (CABG), heart valve repair or replacement, insertion of a pacemaker or an Implantable Cardioverter Defibrillator (ICD), Maze surgery, Aneurysm repair, Heart transplant, insertion of a Ventricular Assist Device (VAD) or Total Artificial Heart (TAH) and trans catheter structural heart surgery ${ }^{19-24}$ in the ICU. In Ethiopia, many cardiologic surgeries are being conducted starting from $2017 .^{25}$

Length of Intensive Care Unit stay or length of stay (LOS) is the average duration patients stay in ICU. In various cardiac centres, clients stay in the ICU not more than a day; while in other centres, they stay up to half day after cardiac surgery. LOS is one of the most significant factors that face hospitals today. ${ }^{26}$

In spite of the beneficial effects cardiac surgery leads to various "short and long-term complications". Potential cardiac problems should be managed in the Intensive Care Unit. ${ }^{27}$ The longer the patient stays in the hospital the higher the risk they will potentially develop healthcare-acquired infections. This leads to lower patient capacities and increased costs. ${ }^{28}$

Hospitals and patients benefit from a shorter LOS. They do not need to cover the burden of treating Hospital Acquired Infections (HAI) and they free up beds for new coming patients. ${ }^{29,30}$ The Average Length of Stay (ALOS) in the hospital is used to measure the efficiency of a health care facility. Globally the average length of hospital stay is 4.5 days according to the agency for health care research and quality. ${ }^{31}$ However, in Ethiopia studies show that the LOS is much higher. $^{32}$

Some literature conducted in different areas mentioned that socio-demographic variables like age, sex, and place of residence, socio-economic factors like monthly income and level of education, organizational factors/hospital legislations such as admission and referral systems, quality of care provided in hospitals, presence or absence of comorbidity, type of surgery have directly or indirectly linked with ICU stay following surgery. Besides the length of ICU stay (LOS) after CABG is determined by the patient's features, before, during, and after surgical procedure care, as well as rules and regulations of the hospital. ${ }^{32-35}$

Little is known for what specific factors can determine the length of hospital stay in the ICU following cardiologic surgery in Ethiopia. And therefore, the objective of this study is to assess what factors can influence length of ICU stay immediately after cardiac surgery in Cardiac Centre Ethiopia.

\section{Methods}

\section{Study Design}

A hospital-based retrospective cross-sectional chart review study was employed from November 15 to May 15/ 2021.

\section{Study Setting}

The study was conducted in cardiac center Ethiopia. Cardiac center Ethiopia is located in Addis Ababa which is selected as a study area. The cardiac center Ethiopia is the only cardiac center in Ethiopia. It was established by Dr. Belay Abegaz in 2009 G.C. Cardiac Centre Ethiopia (CCE) is the first centre in the country to activate cardiac surgery. The centre performs all types of cardiac surgery including rheumatic and valvular heart disease. As the only fully equipped cardiac surgical centre in Ethiopia. Cardiac Centre Ethiopia (CCE) was purposely selected to be the study areas. The hospital 
provides service to patients with the diverse socio-economic background. Besides, there is a high load of CVD patients in the hospital as it is the only cardiac center in the country.

\section{Eligibility Criteria}

Cardiac patient's charts (age $>18$ years old) in which the duration of surgical procedure was undertaken in the last 5 years (2015-1019) in CCE and are eligible for the study.

\section{Sample Size Determination and Sampling Procedure}

The sample size was calculated using a single proportion formula. Since the population size is less than 10, 000, correction formula was employed to estimate the final sample size. Ten percent $(10 \%)$ non-response rate was added. Two hundred forty-eight (248) patient charts were reviewed after all. Lottery method was employed to select the eligible study participants from the cardiac centre Ethiopia chart centre, using Health Service Management and Information System (HMIS) as a sampling frame. Then 248 client charts that have been visited and admitted after cardiac surgery starting from 2015 to 2019 were included in the study. Proportional allocation was conducted for each year from a five-year patients' chart based on population proportionate sampling (PPS). It is estimated using the formula: $(\mathrm{X})=\mathrm{Y}^{*} \mathrm{Z},\left(\mathrm{Y}^{*} \mathrm{FZ}\right.$ in a year) $/ \mathrm{Y}$, where, $\mathrm{FZ}=$ proportion of patient charts per year in $\mathrm{CCE}, \mathrm{X}=$ Final sample size obtained using correction formula (248), $\mathrm{Z}$ is the total number of cardiac patient charts in the respective year.

\section{Study Instrument}

A chart review was conducted in the selected study area using guide checklist. The guide checklist contains sociodemographic variables and the length of ICU stay related guiding tool. The tool was developed from different literatures and modified together with the highly skilled professionals in the field like nurse, doctors and professors in the Nursing field.

\section{Operational Definition}

Length of stay $=$

the length of an inpatient episode of care, calculated from the day of admission to the day of discharge, and based on the number of nights spent in the hospital. Patients admitted and discharged on the same day have a length of stay of less than one day. The number of days between admission and discharge from an inpatient care facility.

- The average length of ICU stays (ALICUS): refers to the average number of days that patients spend in ICU (postsurgery). The average length of stay (ALS) in ICU is used to gauge the efficiency of a healthcare facility. According to the "Agency for Healthcare Research and Quality". ${ }^{3}$

- Length of ICU stay (LICUS): in the current study length of stay was calculated as either prolonged or not after calculating ALOS.

- Short ICU stays = patients who had less than or equal to the "Average Length of ICU Stay (ALICUS) after cardiac surgery."

- Prolonged ICU stays= patients who had longer than the "Average Length of ICU Stay (ALOHS) after cardiac surgery."

\section{Data Analysis}

Data was entered into EPI Info version 7.2 and exported to SPSS version 25 for analysis. Descriptive statistics, such as mean, frequency and percentage was used to compute continuous and categorical variables respectively. Both bivariate and multivariate logistic regression analyses were employed to determine independently related factors of prolonged ICU stay. The bivariate analysis was exported to multivariate analysis when $\mathrm{P}<0.25$ to control the possible effect of confounders. Adjusted odds ratio (AOR) with 95\% Confidence Interval (CI) and P-value less than or equal to 0.05 were used to select variables related to prolonged ICU stay after surgery. 


\section{Results}

\section{Socio Demographic Characteristics}

A total of 248 charts were reviewed. The mean age of the participants from the chart review was $32.99+10.45$ years with 19 the youngest and 67 the oldest. As shown in (Table 1), majority of the participants were female $159(64.1 \%)$. As few as $16(6.5 \%)$ of the charts reviewed were having history of smoking cigarettes, while majority $242(97.6 \%)$ of the surgeries conducted were elective and 103 (41.6\%) of the surgeries conducted were for Mitral Valve Replacement (MVR). Majority of the patients were diagnosed for Rheumatoid heart diseases (RHD).

\section{Clinical Characteristics of the Respondents}

As shown in (Table 2) patients were assessed for presence of comorbidity regardless of their primary diagnosis. Therefore $179(72.2 \%)$ and $73(29.4 \%)$ patients had pulmonary hypertension and history of respiratory diseases respectively. As few as $4(1.6 \%)$ and $7(2.8 \%)$ had congestive heart failure and myocardial infarction respectively. Seventeen (6.9\%) had Diabetes Mellitus (DM) and only 8(3.2\%) had renal failure.

\section{Clinical Characteristics}

As shown in (Table 3) almost all 241 (97.2\%) patients had used thrombolytic agent's and 234 (94.4\%) of patients had 40 and above left ventricular ejection fraction as reviewed from their charts (Figure 1). According to the current chart review study the mean Haematocrits level of the patients was $38.07+5.73$ with 25 the lowest and the highest 49 .

\section{Complication Following Cardiac Surgery}

Only one patient found to develop sepsis following cardiac surgery, 47 (19\%) and 3 (1.2\%) develop bleeding and depression respectively following cardiac surgery in the ICU (Table 4).

Table I Socio Demographic Characteristics of Patients Charts Review for Length of ICU Stay Following Cardiac Surgery in Cardiac Center Ethiopia 202I ( $\mathrm{n}=248)$

\begin{tabular}{|c|c|c|c|}
\hline Variable & Category & Frequency (n) & Percentage (\%) \\
\hline \multirow[t]{2}{*}{ Sex } & Male & 89 & 35.9 \\
\hline & Female & 159 & 64.1 \\
\hline \multirow[t]{3}{*}{ Age } & 18-32 years & 140 & 56.5 \\
\hline & 33-48years & 89 & 35.9 \\
\hline & $>48$ years & 19 & 7.7 \\
\hline \multirow[t]{2}{*}{ Smoking history } & Yes & 16 & 6.5 \\
\hline & No & 232 & 93.5 \\
\hline \multirow[t]{2}{*}{ Surgical urgency } & Elective surgery & 242 & 97.6 \\
\hline & Emergency surgery & 6 & 2.4 \\
\hline \multirow[t]{2}{*}{ Diagnosis before surgery } & RHD & 198 & 79.8 \\
\hline & $\mathrm{CHD}$ & 50 & 20.2 \\
\hline \multirow[t]{9}{*}{ Name of surgical procedures } & Mitral valve replacement & 103 & 41.5 \\
\hline & Aortic valve repair & 50 & 20.2 \\
\hline & Tricuspid valve repair & 24 & 9.7 \\
\hline & Left aortic excision & 15 & 6 \\
\hline & Atrial septal defect & 22 & 8.9 \\
\hline & Ventricular septal defect & 8 & 3.2 \\
\hline & CABG & 6 & 2.4 \\
\hline & Pericarditis & 5 & 2 \\
\hline & Combination of AVR, MVR, TVR, and other & 15 & 6 \\
\hline
\end{tabular}

Abbreviations: RHD, rheumatoid heart disease; CHD, congenital heart disease; CABG, coronary artery bypass grafting; AVR: aortic valve repair; MVR, mitral valve repair, TVR, tricuspid valve repair. 
Table 2 Comorbidities of Patients from Charts Review for Length of ICU Stay Following Cardiac Surgery in Cardiac Centre Ethiopia 202I ( $n=248)$

\begin{tabular}{|l|l|l|l|}
\hline Comorbidities & Category & Frequency (n) & Percentage (\%) \\
\hline Diabetes & Yes & 17 & 6.9 \\
Hypertension & No & 231 & 93.1 \\
Renal failure & Yes & 39 & 15.7 \\
& No & 209 & 84.3 \\
History of respiratory disease & Yes & 8 & 3.2 \\
& No & 240 & 96.8 \\
CHF ${ }^{a}$ on admission, & Yes & 73 & 29.4 \\
& No & 175 & 70.6 \\
Pulmonary HTN $^{b}$ & Yes & 4 & 1.6 \\
History of Angina & No & 244 & 98.4 \\
& Yes & 179 & 72.2 \\
LMCA $^{c}$ disease & No & 69 & 27.8 \\
MI $^{d}$ & Yes & 9 & 3.6 \\
& No & 239 & 96.4 \\
& Yes & 6 & 2.4 \\
\hline
\end{tabular}

Abbreviations: ${ }^{a} \mathrm{CHF}$, congestive heart failure; ${ }^{\mathrm{b}} \mathrm{HTN}$, hypertension; ${ }^{\mathrm{C} L M C A}$, left main coronary artery; ${ }^{\mathrm{d}} \mathrm{Ml}$, myocardial infarction.

Table 3 Medication and Laboratory Result of Patients from Charts Review for Length of ICU Stay Following Cardiac Surgery in Cardiac Center Ethiopia 202I ( $n=248)$

\begin{tabular}{|l|l|l|l|}
\hline Medication and Laboratory Result & Category & Frequency (n) & Percentage (\%) \\
\hline Use of thrombolysis & Yes & 241 & 97.2 \\
Left ventricular ejection fraction & No & 7 & 2.8 \\
& $\geq 40 \%$ & 234 & 94.4 \\
\hline
\end{tabular}

\section{Average Length of ICU Stay Following Cardiac Surgery}

According to the current study conducted in cardiac centre Ethiopia, Addis Ababa, Ethiopia the length of Intensive Care Unit (ICU) stay following cardiac surgery was $3.79+1.7$ days ranging from 1 to 9 days. Accordingly, 122 (49.2\%) of the

\section{LEVEL OF HCT FOLLOWING CARDIAC SURGERY}

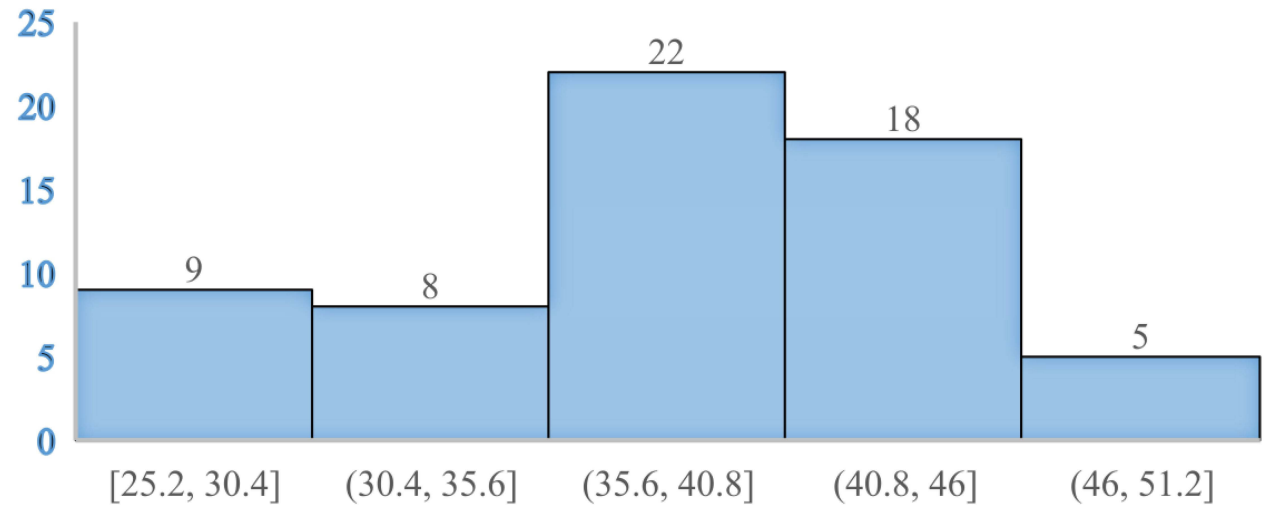

Figure I Haematocrits (HCT) level of charts reviewed following cardiac surgery among patients attending Cardiac Center Ethiopia 202I ( $\mathrm{n}=248$ ). 
Table 4 Complications of Cardiac Surgery Among Patients Stayed Cardiac Center Ethiopia ICU Ethiopia 202I ( $n=248)$

\begin{tabular}{|l|l|l|l|}
\hline Complications After Cardiac Surgery & Category & Frequency (n) & Percentage (\%) \\
\hline Sepsis & Yes & 1 & 0.4 \\
Bleeding & No & 247 & 99.6 \\
& Yes & 47 & 19 \\
Post operation Depression & No & 201 & 81 \\
& Yes & 3 & 1.2 \\
\hline
\end{tabular}

patients had shorter length of ICU stay and $126(50.8 \%)$ had longer length of ICU stay immediately after cardiac surgery in Cardiac Centre Ethiopia (Figure 2).

\title{
Average Length of ICU Stay Following Cardiac Surgery and Associated Factors
}

To identify factors associated with prolonged ICU stay following cardiac surgery, logistic regression model was fitted. On binary logistic regression analysis, previous history of smoking history having comorbidities such as respiratory distress and pulmonary hypertension, use of thrombolytic medications, having two or more heart surgeries, lower Hct level, postsurgery bleeding and medication consultations were associated with length of ICU sat following cardiac surgery. Finally, after obtaining statistically significant variables at $\mathrm{p}<0.05$ in binary logistic regression analysis, multiple logistic regression analysis was carried out to see the independent predictors of prolonged length of ICU stay following cardiac surgery. The multivariate logistic regression was carried out by taking prolonged length of ICU stay as a covariate in addition to those variables where significant association was obtained in binary logistic regression. After adjusting potential confounders, previous history of smoking, having more than one surgery procedure and post cardiac surgery bleeding complication remained statistically significant for prolonged intensive care unit stay following cardiac surgery in the current study (Table 5).

\section{LENGTH OF ICU STAY FOLLOWING CARDIAC SURGERY}

\author{
SHORT ICU STAY $\quad$ LONGER ICU STAY
}

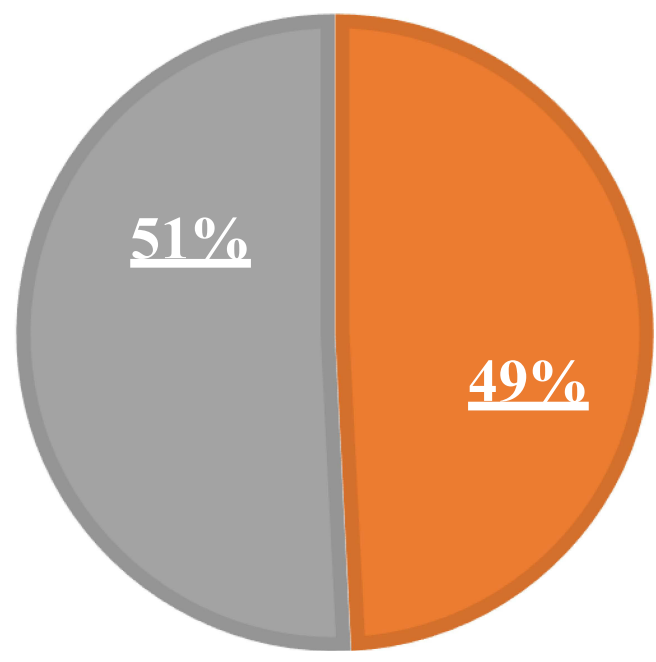

Figure 2 Length of ICU stay following cardiac surgery among patients attending Cardiac Center Ethiopia 202I ( $\mathrm{n=248).}$ 
Table 5 Factors Associated Length of ICU Stay Following Cardiac Surgery in Cardiac Center Ethiopia 202I (n=248)

\begin{tabular}{|c|c|c|c|c|c|c|c|}
\hline \multirow[t]{2}{*}{ Variables } & \multirow[t]{2}{*}{ Category } & \multicolumn{2}{|c|}{ Length of ICU Stay } & \multirow[t]{2}{*}{ COR $(95 \% \mathrm{Cl})$} & \multirow[t]{2}{*}{$\mathbf{P}$} & \multirow[t]{2}{*}{ AOR $(95 \% \mathrm{Cl})$} & \multirow[t]{2}{*}{$\mathbf{P}$} \\
\hline & & Short & Long & & & & \\
\hline \multirow[t]{2}{*}{ Smoking history } & Yes & $3(1.2 \%)$ & $13(5.2 \%)$ & $4.6(1.26,16.438)$ & $0.02 * *$ & $4.6(1.23,17.4)$ & $0.023 * *$ \\
\hline & No & $119(48 \%)$ & $113(45.6 \%)$ & 1 & & 11 & \\
\hline \multirow[t]{2}{*}{ Respiratory distress } & No & $78(31.5 \%)$ & $97(39.1 \%)$ & I.89(I.08,3.289) & $0.025^{* *}$ & $1.58(0.85,2.94)$ & 0.14 \\
\hline & Yes & $44(17.7 \%)$ & $29(11.7 \%)$ & 1 & & I & \\
\hline \multirow[t]{2}{*}{ Pulmonary HTN } & Yes & $84(33.9 \%)$ & $95(38.3 \%)$ & I.38(0.794,2.42) & $0.25 *$ & $\mathrm{I}(0.56,1.95)$ & 0.88 \\
\hline & No & $38(15.3 \%)$ & $31(12.5 \%)$ & I & & 1 & \\
\hline \multirow[t]{2}{*}{ Use of thrombolytic agents } & Yes & $117(47.2 \%)$ & $124(50 \%)$ & $2.7(0.5,13.923)$ & $0.25 *$ & I.5(0.27,7.87) & 0.66 \\
\hline & No & $5(2 \%)$ & $2(0.8 \%)$ & 1 & & 1 & \\
\hline \multirow[t]{2}{*}{ Number of surgeries } & Less 2 & 119 & 114 & $0.24(0.066,0.87 I)$ & $0.03 * *$ & $0.23(0.06,0.867)$ & $0.03 * *$ \\
\hline & Two or more surgeries & 3 & 12 & 1 & & I & \\
\hline Hct level & & & & $0.96(0.921,1.007)$ & $0.09 *$ & $0.96(0.917,1.08)$ & 0.104 \\
\hline \multirow[t]{2}{*}{ Post-surgery bleeding } & Yes & $10(4 \%)$ & $37(14.9 \%)$ & $4.65(2.2,9.87)$ & $0.00 * *$ & $4.32(1.8,10.2)$ & $0.00 I^{* *}$ \\
\hline & No & $\mathrm{I} / 2(45.2 \%)$ & $89(35.9 \%)$ & 1 & & $\mathrm{I}$ & \\
\hline \multirow[t]{2}{*}{ Medication consultation } & Yes & $6(2.4 \%)$ & $17(6.9 \%)$ & 3.(I.147,7.92) & $0.025^{* *}$ & $0.93(0.29,2.96)$ & 0.899 \\
\hline & No & $116(46.8 \%)$ & $109(44 \%)$ & 1 & & I & \\
\hline
\end{tabular}

Notes: *P value $\leq 0.25 ;{ }^{* *} \mathrm{p}$ value $\leq 0.05$.

Abbreviations: ICU, intensive care unit; COR, crude odds ratio; AOR, adjusted odds ratio; $\mathrm{Cl}$, confidence interval; $\mathrm{HTN}$, hypertension; Hct, haematocrit.

\section{Discussion}

The current study assess the length of ICU stay and determining factors following cardiac surgery in Cardiac Centre Ethiopia. Accordingly, the length of Intensive Care Unit (ICU) stay following cardiac surgery was $3.79+1.7$ days ranging from 1 to 9 days. The current finding is consistent compared to the study conducted in Canada at Queen Elizabeth II health sciences center, Halifax, on which explored that length of stay following surgery was, average, 3 days for patients with new-onset postoperative atrial fibrillation following cardiac surgery ${ }^{34}$ and a study conducted in St. Michael's hospital in Canada Toronto among 265 patients having cardiac surgery

overall, $14.4 \%$ of the patients had a long ICU length of stay with six patients having stays $>10$ days. The mean ICU stay was 2.02 (SD 3.6992) days while the median stay was 1 day. ${ }^{35}$

However the current study confirm shorter duration of ICU stay compared to a study conducted in in "St. George's hospital university of London" United Kingdom (UK) which explored that "the combined association of depression and socioeconomic status with a length of post-operative hospital stay following coronary artery bypass graft surgery:" the study showed that the average length of stay for patients in St. George's hospital was "7 days, with a range of 4 to 66 days". ${ }^{36}$ This discrepancy may be due to difference in technological advancement of surgical procedures, patients smoking history and post operation complications in the later study.

In the other way the current study average length of ICU stay following cardiac surgery is a little bit short compared to a cohort study of "impact of bleeding complications on length of stay and critical care utilization in cardiac surgery patients in England" which showed that

LOS was 15.4 days $(\mathrm{SD}=14.4)$ and 10.4 days $(\mathrm{SD}=8.9)$ among patients with and without bleeding complications, respectively. After adjustment for patient and procedure characteristics, the adjusted means were 13.6 days and 10.5 days for patients with and without bleeding complications, respectively (adjusted ratio $=1.29 ; 95 \%$ CI: $1.23,1.36 ; \mathrm{p}<0.0001 ; \mathrm{MID}=3.1$ days. $^{37}$

This discrepancy may be due to the fact that difference in the methodology of the previous study or high number of study participants in the previous study.

The current finds out that 103 (41.6\%) of the surgeries conducted were for Mitral Valve Replacement (MVR). Majority of the patients were diagnosed for Rheumatoid heart diseases (RHD). This is congruent compared to a study a follow-up study conducted in one university hospital of France. Intensive care unit stay was significantly shorter in the 
Mini-Invasive Aortic Valve Replacement-Enhanced Recovery After Surgery (MIAVR-ERAS) group compared with that of the traditional Mini Invasive Aortic Valve Replacement (MIAVR) care group, with 7 (6.5-8) days and 10 (9-13.5) days, respectively. $(\mathrm{p}<0.001)$. $^{38}$

This congruency may be due to the fact that "Mini Invasive Aortic Valve Replacement (MIAVR)" is the commonest surgery world-wide.

According to a controlled trial follow up a recent study of Journal of Cardiothoracic Surgery conducted in England more than 82 patients had longer ICU, LOS which is greater than 3 days and most patients stayed 5-11 days in the hospital, with an average hospital length of stay after cardiac surgery 8 days. ${ }^{39}$ This is congruent compared to the current study as it revealed that $122(49.2 \%)$ of the patients had shorter length of ICU stay and $126(50.8 \%)$ had longer ICU stay following cardiac surgery.

According to a study conducted in St. Michael's hospital in Canada Toronto among 265 patients having cardiac surgery

overall, $14.4 \%$ of the patients had a long ICU length of stay with six patients having stays $>10$ days. The mean ICU stay was 2.02 (SD 3.6992) days while the median stay was 1 day. The overall hospital mortality rate in the study population was $3.6 \% .{ }^{35}$

This contradicts the current finding in which more than $51 \%$ of the study participants had longer ICU hospital stay following cardiac surgery. This discrepancy may be due to shorter length of ICU stay and too many patients stay away from the mean level of the ICU stay because of unidentified reasons.

A controlled trial study conducted among 265 patients undergoing primary coronary artery bypass grafting in New Jersey, USA revealed that

Fifty-nine (25\%) patients required greater than 6 days of postoperative hospitalization. Prolonged hospital stays (prolonged length of hospital stay 6 days). Patients with prolonged oxygen desaturation and patients with postoperative cognitive decline had a significantly prolonged ICU stay following cardiac surgery. ${ }^{40}$

Compared to the current study the American study shows very few patients 59 (25\%) while the current study revealed 126 $(50.8 \%)$ had stayed longer in the ICU following cardiac surgery. This discrepancy may be due to higher post-surgery complication in the current study or very specialized advanced ICU equipment's, post-surgical patient protection in the late study.

A study conducted in Canada on "the impact of new-onset atrial fibrillation on in-hospital mortality following cardiac Surgery" suggested that rates of gastrointestinal complications and septicaemia increased length of stay in patients undergo cardiac surgery. ${ }^{34}$ This is consistent compared to the current study which explored having more than one surgery having comorbidity and post-surgery complication like bleeding associated to prolonged ICU stays.

An England cohort study of "impact of bleeding complications on length of stay and critical care utilization in cardiac surgery patients in England" conducted among 7774 eligible cardiac surgery patients revealed that

reoperation for bleeding complications was associated with a larger increase in mean post-procedure LOS: patients with a bleeding-relation reoperation had an adjusted mean LOS of 14.7 days versus 10.7 days in patients without a reoperation (adjusted ratio $=1.37 ; 95 \%$ CI: $1.12,1.69 ; \mathrm{p}=0.002 ; \mathrm{MID}=4.0$ days). Eighty-seven percent of patients with bleeding complications spent one or more days in critical care following surgery (mean= 7.5 days, $\mathrm{SD}=10.8$ ), as compared with $82 \%$ of patients without bleeding complications (mean $=4.0$ days, $\mathrm{SD}=5.4) .{ }^{37}$

This is extremely congruent with our study.

The study conducted on determinants of the length of stay in intensive care and in hospital after coronary artery surgery in New Castle, England showed that

absence of previous myocardial infarction and good renal function were associated with lower ICU stay. Age, sex, body mass index, obesity, diabetes, hypertension, a history of obstructive pulmonary disease, angina grade, exercise tolerance, and unstable angina were not significantly associated with time spent on the intensive care unit. ${ }^{41}$

This is congruent compared to our study in which social demographic characteristics and clinical factors were not significantly associated with time spent on the intensive care unit. 
An observational study conducted in Israel among 105 patients over three months' period showed that "nurse and physician change of shifts and admissions to hospital wards were found to be significant factors associated with LOS". ${ }^{28}$ This contradicts with the current finding in which organizational factors have no association with length of ICU stay, except most complications in the current study may have been developed from poor organizational factors of patient management following cardiac surgery.

According to the Oman retrospective observational study, "factors associated with prolonged total postoperative LOS, number of complications was the most important determinant of postoperative LOS" ${ }^{26}$ This is consistent compared to our study as our study identified post-surgery complication such as bleeding determine length of ICU stay.

\section{Conclusion}

The length of Intensive Care Unit stay following cardiac surgery was $3.79+1.7$ days ranging from 1 to 9 days, and 126 (50.8\%) had longer length of ICU stay after cardiac surgery in Cardiac Centre Ethiopia.

Previous smoking history leads to higher cardiovascular disease that lead to surgery and having more than one surgery procedure is associated with prolonged length of ICU stay. Post cardiac surgery complications such as bleeding is highly associated with prolonged cardiac surgery Intensive Care Unit stay after surgery.

\section{Abbreviations}

ALOS, average length of hospital stay, AOR, adjusted odd ratio, BMI, body mass index, CABG, coronary artery bypass grafting, CC, cardiac catheterization, CHF, congestive heart failure, CI, confidence interval, COR, crude odd ratio, CVD, cardio vascular disease, ERAS, enhanced recovery after surgery, GBD, Global Burden of Diseases, HAI, healthcare acquired infection, ICD, implantable cardiovascular defibrillator, ICU, intensive care unit, LOS, length of hospital stay, PCI, percutaneous coronary intervention, SD, standard deviation, SPHMMC, Saint Paul's Hospital Millennium Medical College, USA, United States of America, VAD, ventricular assisting device, WHO, World Health Organization.

\section{Authors' Information}

TT holds MSc in Oncology Nursing with more than 7 years' experience in nursing, teaching and research. TT is currently serving as Lecturer at Saint Paul's hospital millennium medical college, oncology nursing, Addis Ababa, Ethiopia. techanetesfaye@yahoo.com).

EN holds MSc maternity and reproductive health Nursing with more than 10years' experience in nursing, teaching and research. EN is currently serving as Assistant Lecturer at Saint Paul's hospital millennium medical college, neonatal and maternity nursing, Addis Ababa, Ethiopia.

FL holds MSC in Adult health nursing with more than 9 years' experience in nursing, teaching and research. FL is currently serving as Assistant Lecturer at Saint Paul's hospital millennium medical college, medical surgical nursing, Addis Ababa, Ethiopia.

TF holds MSC in Cardiothoracic nursing with more than 9 years' experience in nursing.TF is currently serving as nurse professional at Saint Paul's hospital millennium medical college, cardiothoracic nursing clinical department, Addis Ababa, Ethiopia.

\section{Data Sharing Statement}

The data analyzed during the current study is available from the corresponding author on reasonable request.

\section{Ethics Approval and Consent to Participate}

To conform the Declaration of Helsinki (1964) and Population Screening Act, Saint Paul's Hospital Millennium Medical College Institutional Review Board approved the study. Information was collected from patient charts only, after obtaining written consent from both Cardiac Center Ethiopia (CCE) and Saint Paul's Hospital Millennium Medical College (SPHMMC) school of nursing. Saint Paul's Hospital Millennium Medical College research review board wrote letter of cooperation and covered the cost of the research. The main objective of the study was for the fulfillment of the requirements for the degree of master of science in Cardiothoracic surgery in nursing. Because of this permission of data 
collection from patient charts without patient consent was granted from both hospitals and data was collected accordingly.

\section{Acknowledgments}

Our gratitude goes to SPHMMC, School of Nursing for its financial support. Our recognition also goes to data collectors, supervisors, nursing staffs and authorities of the hospital. Finally, we would like to thank the CCE triage and record room officers who were willing and cooperative to ease our chart review difficulty.

\section{Author Contributions}

All authors made a significant contribution to the work reported, whether that is in the conception, study design, execution, acquisition of data, analysis and interpretation, or in all these areas; have drafted or written, or substantially revised or critically reviewed the article; have agreed on the journal to which the article was submitted; reviewed and agreed on all versions of the article before submission, during revision, the final version accepted for publication, and any significant changes introduced at the proofing stage; and agree to take responsibility and be accountable for the contents of the article.

\section{Funding}

This study was conducted in collaboration with Saint Paul's Hospital Millennium Medical College. Every step of the project was followed by SPHMMC, School of Nursing. The university has no role in designing, analysis and writing of the study.

\section{Disclosure}

The authors declare that they have no conflicts of interest for this work.

\section{References}

1. Csige I, Ujvárosy D, Szabó Z, et al. The impact of obesity on the cardiovascular system. J Diabetes Res. 2018;2018:1-12. doi:10.1155/2018/ 3407306

2. Roth GA, Johnson C, Abajobir A, et al. Global, regional, and national burden of cardiovascular diseases for 10 causes, 1990 to $2015 . \mathrm{J}$ Am Coll Cardiol. 2017;70(1):1-25. doi:10.1016/j.jacc.2017.04.052

3. Fornaro M, Solmi M, Veronese N, et al. The burden of mood-disorder/cerebrovascular disease comorbidity: essential neurobiology, psychopharmacology, and physical activity interventions. Int Rev Psychiatry. 2017;29(5):425-435. doi:10.1080/09540261.2017.1299695

4. World Health Organization. Cardiovascular diseases (CVDs): keyfacts. Fact sheet; 2017.

5. World Health Organization. Fact sheet: cardiovascular diseases (CVDs). World Heal Organization; 2017.

6. World Health Organization. World Health Organization (WHO)/Fact sheet/Cardiovascular diseases (CVDs). WHO; 2017.

7. Bowry ADK, Lewey J, Dugani SB, Choudhry NK. The burden of cardiovascular disease in low- and middle-income countries: epidemiology and management. Can J Cardiol. 2015;31(9):1151-1159. doi:10.1016/j.cjca.2015.06.028

8. Lear SA, Hu W, Rangarajan S, et al. The effect of physical activity on mortality and cardiovascular disease in 130000 people from 17 high-income, middle-income, and low-income countries: the PURE study. Lancet. 2017;390(10113):2643-2654. doi:10.1016/S0140-6736(17)31634-3

9. Rodriguez-Fernandez R, Amiya R, Wyber R, Widdodow W, Carapetis J. Rheumatic heart disease among adults in a mining community of Papua, Indonesia: findings from an occupational cohort. Heart Asia. 2015;7(2):1-5. doi:10.1136/heartasia-2015-010641

10. Carrillo-Larco RM, Miranda JJ, Li X, et al. Prevalence of pragmatically defined high CV risk and its correlates in LMIC A report from 10 LMIC areas in Africa, Asia, and South America. Glob Heart. 2016;11(1):27-36. doi:10.1016/j.gheart.2015.12.004

11. Murray CJL, Lopez AD. Global mortality, disability, and the contribution of risk factors: global burden of disease study. Lancet. 2013;349 (9063):1436-1442. doi:10.1016/S0140-6736(96)07495-8

12. Misganaw A, Mariam DH, Ali A, Araya T. Epidemiology of major non-communicable diseases in Ethiopia: a systematic review. $J$ Health Popul Nutr. 2014; 32:1.

13. Nigatu T. Epidemiology, complications and management of diabetes in Ethiopia: a systematic review. J Diabetes. 2012;4(2):174-180. doi:10.1111/ j.1753-0407.2011.00181.x

14. Celermajer DS, Chow CK, Marijon E, et al. Cardiovascular disease in the developing world: prevalences, patterns, and the potential of early disease detection. J Am Coll Cardiol. 2012; 60:1207-1216.

15. Deye N, Vincent F, Michel P, Ehrmann S, Da Silva D, Piagnerelli M. The tanzanian cardiovascular disease (Tancard) registry: fromx pilot to full phase. Cardiovasc J Afr. 2015;21(10):25-27.

16. Mozaffarian D, Benjamin EJ, Go AS, et al. Executive summary: heart disease and stroke statistics-2016 update: a report from the American Heart Association. Circulation. 2016; 133:447-454.

17. Nesteruk J, Duckers HJ, Strauer BE, Steinhoff G. Heart. In: Regenerative Medicine - from Protocol to Patient: 5 Regenerative Therapies II. 3rd ed; 2016. 
18. Maganti K, Rigolin VH, Sarano ME, Bonow RO. Valvular heart disease: diagnosis and management. In: Mayo Clinic Proceedings; 2010.

19. Dangas GD, Weitz JI, Giustino G, Makkar R, Mehran R. Prosthetic heart valve thrombosis. J Am Coll Cardiol. 2016;68(24):2670-2689. doi:10.1016/j.jacc.2016.09.958

20. Rankin JS, Hammill BG, Ferguson TB, et al. Determinants of operative mortality in valvular heart surgery. J Thorac Cardiovasc Surg. 2016;152 (3):681-682. doi:10.1016/j.jtcvs.2016.05.050

21. Tikkanen AU, Nathan M, Sleeper LA, et al. Predictors of postoperative rehabilitation therapy following congenital heart surgery. J Am Heart Assoc. 2018; 7:e008094.

22. Quaife-Ryan GA, Sim CB, Ziemann M, et al. Multicellular transcriptional analysis of mammalian heart regeneration. Circulation. 2017;136 (12):1123-1139. doi:10.1161/CIRCULATIONAHA.117.028252

23. Knirsch W, Nadal D. Infective endocarditis in congenital heart disease. Eur J Pediatr. 2011;170(9):1111-1127. doi:10.1007/s00431-011-1520-8

24. Gandaglia A, Bagno A, Naso F, Spina M, Gerosa G. Cells, scaffolds and bioreactors for tissue-engineered heart valves: a journey from basic concepts to contemporary developmental innovations. Eur J Cardiothorac Surg. 2011;39(4):523-531. doi:10.1016/j.ejcts.2010.07.030

25. Leuner CJ, Weldegerima AH. Cardiology services in Ethiopia. Eur Heart J. 2018; 39:2699-2700.

26. Almashrafi A, Alsabti H, Mukaddirov M, Balan B, Aylin P. Factors associated with prolonged length of stay following cardiac surgery in a major referral hospital in Oman: a retrospective observational study. BMJ Open. 2016;6(6):1-7. doi:10.1136/bmjopen-2015-010764

27. Zarrizi M, Paryad E, Khanghah AG, Leili EK, Faghani H. Predictors of length of stay in intensive care unit after coronary artery bypass grafting: development a risk scoring system. Brazilian J Cardiovasc Surg. 2021;36(1):57-63.

28. Bashkin O, Caspi S, Haligoa R, Mizrahi S, Stalnikowicz R. Organizational factors affecting length of stay in the emergency department: initial observational study. Isr J Health Policy Res. 2015;4(1). doi:10.1186/s13584-015-0035-6

29. Mithiran H, Kunnath Bonney G, Bose S, et al. A score for predicting acute kidney injury after coronary artery bypass graft surgery in an Asian population. J Cardiothorac Vasc Anesth. 2016;30(5):1296-1301. doi:10.1053/j.jvca.2016.03.135

30. Kinnunen EM, Juvonen T, Airaksinen KEJ, et al. Clinical significance and determinants of the universal definition of perioperative bleeding classification in patients undergoing coronary artery bypass surgery. J Thorac Cardiovasc Surg. 2014;148(4):1640-1646.e2. doi:10.1016/j. jtcvs.2014.07.040

31. Awad A, Bader-el-den M, McNicholas J. Patient length of stay and mortality prediction: a survey. Heal Serv Manag Res. 2017;30(2):105-120. doi:10.1177/0951484817696212

32. Alemu GH, Negari KG, Rodamo KM, Hirigo AT. Factors associated with the length of stay in emergency departments in Southern-Ethiopia. $B M C$ Res Notes. 2019;12(1). doi:10.1186/s13104-019-4271-7

33. OECD. Length of hospital stay (indicator). OECD; 2020.

34. Kalavrouziotis D, Buth KJ, Ali IS. The impact of new-onset atrial fibrillation on in-hospital mortality following cardiac surgery. Chest. 2014;131 (3):833-839. doi:10.1378/chest.06-0735

35. Tu JV, Mazer CD. Can clinicians predict ICU length of stay following cardiac surgery? Can J Anaesth. 2012;43(8):789-794. doi:10.1007/ BF03013030

36. Poole L, Leigh E, Kidd T, Ronaldson A, Jahangiri M, Steptoe A. The combined association of depression and socioeconomic status with length of post-operative hospital stay following coronary artery bypass graft surgery: data from a prospective cohort study. J Psychosom Res. 2014;76 (1):34-40. doi:10.1016/j.jpsychores.2013.10.019

37. Al-Attar N, Johnston S, Jamous N, et al. Impact of bleeding complications on length of stay and critical care utilization in cardiac surgery patients in England. $J$ Cardiothorac Surg. 2019;14(1):1-10. doi:10.1186/s13019-019-0881-3

38. Zaouter C, Oses P, Assatourian S, Labrousse L, Rémy A, Ouattara A. Reduced length of hospital stay for cardiac surgery-implementing an optimized perioperative pathway: prospective evaluation of an enhanced recovery after surgery program designed for mini-invasive aortic valve replacement. J Cardiothorac Vasc Anesth. 2019;33(11):3010-3019. doi:10.1053/j.jvca.2019.05.006

39. Baribeau Y, Westbrook B, Baribeau Y, Maltais S, Boyle EM, Perrault LP. Active clearance of chest tubes is associated with reduced postoperative complications and costs after cardiac surgery: a propensity matched analysis. J Cardiothorac Surg. 2019;14(1):1-9. doi:10.1186/s13019-019-0999-3

40. Slater JP, Guarino T, Stack J, et al. Cerebral oxygen desaturation predicts cognitive decline and longer hospital stay after cardiac surgery. Ann Thorac Surg. 2011;87(1):36-45. doi:10.1016/j.athoracsur.2008.08.070

41. Mounsey JP, Griffith MJ, Heaviside DW, Hedley Brown A, Reid DS. Determinants of the length of stay in intensive care and in hospital after coronary artery surgery. Br Heart J. 2011;73(1):92-98. doi:10.1136/hrt.73.1.92

Research Reports in Clinical Cardiology

Dovepress

Publish your work in this journal

Research Reports in Clinical Cardiology is an international, peer-reviewed, open access journal publishing original research, reports, editorials, reviews and commentaries on all areas of cardiology in the clinic and laboratory. The manuscript management system is completely online and includes a very quick and fair peer-review system. Visit http://www.dovepress.com/testimonials.php to read real quotes from published authors.

Submit your manuscript here: http://www.dovepress.com/research-reports-in-clinical-cardiology-journal 